\title{
IMPLEMENTASI PENGUATAN PEDIDIKAN KARAKTER (PPK) NASIONALISME DAN RELIGIUS DALAM PEMBELAJARAN IPS DI SMP NASIMA SEMARANG
}

\author{
Sri Puji Lestari, Tukidi, Fredy Hermanto \\ Program Studi Pendidikan IPS \\ sripujilestari1996@gmail.com
}

\begin{abstract}
The purposes of this research (1) to find out the Implementation of Nationalism and Religious Strengthening Character Education in learning social studies; (2) identify the supporting and inhibiting factors for the Implementation of Nationalism and Religious Strengthening Character Education in learning social studies at Junior High School of Nasima Semarang. The research method used was qualitative. The data collection techniques used were observation, interviews, and documentation. The data were analyzed using the Mile and Huberman Interactive Analysis. The data validity checking technique was using source triangulation. The results showed that: (1) the Implementation of Character buildings in learning social studies was carried out in all learning processes, including learning plan, learning implementation, and learning avaluation. (2) The barriers faced by social science's teachers of Junior High School of Nasima Semarang were related to the efforts of consistency and continuity in internalizing the value of Character buildings, especially nationalism and religion character. The supporting factors for the mplementation of Nationalism and Religious Character buildings in learning social studies at Junior High School of Nasima Semarang were qualified teachers, and the complete facilities and infrastructure.
\end{abstract}

Keywords: Character buildings, Nationalism, Religious

Abstrak
Tujuan penelitian ini: (1) mengetahui implementasi PPK nasionalisme dan religius dalam pembelajaran IPS; (2) mengidentifikasi faktor pendukung dan penghambat implementasi PPK nasionalisme dan religius dalam pembelajaran IPS di SMP Nasima Semarang. Metode penelitian yang digunakan adalah kualitatif. Teknik pengumpulan data menggunakan observasi, wawancara, dan dokumentasi. Data dianalisis menggunakan model Miles dan Huberman yaitu analisis interaktif. Teknik pemeriksaan keabsahan data dengan triangulasi sumber. Hasil penelitian menunjukkan bahwa: (1) Implementasi PPK Nasionalisme dan Religius dalam pembelajaran IPS dilakukan dalam semua proses pembelajaran, meliputi perencanaan pembelajaran, pelaksanaan pembelajaran, serta evaluasi pencapaian belajar; (2) Hambatan yang dihadapi guru IPS di SMP Nasima terkait dengan upaya konsistensi dan kontinuitas dalam menginternalisasikan nilai-nilai Penguatan Pendidikan Karakter (PPK) Nasionalisme dan Religius dalam diri siswa. Adapun faktor pendukung Implementasi PPK Nasionalisme dan Religius dalam pembelajaran IPS di SMP Nasima Semarang meliputi guru yang berkualitas, serta sarana dan prasarana yang lengkap.

Kata Kunci: Pendidikan Karakter, Nasionalisme, Religius 


\section{PENDAHULUAN}

Undang-Undang No. 20 Tahun 2003 tentang Tujuan Pendidikan Nasional telah menjelaskan tujuan pendidikan yakni mengembangkan potensi peserta didik agar menjadi manusia yang beriman dan bertakwa kepada Tuhan Yang Maha Esa, berakhlak mulia, sehat, berilmu, cakap, kreatif, mandiri, dan menjadi warga negara yang demokratis serta bertanggung jawab. Thomas Lickona dalam bukunya yang berjudul The Return of Character Education mengusung tiga unsur pokok dalam pendidikan karakter, yaitu mengetahui kebaikan (knowing the good), mencintai kebaikan (desiring the good), dan melakukan kebaikan (doing the good) (Dalmeri, 2014:271).

Guna mencapai tujuan pendidikan berupa pengembangan karakter tersebut, pemerintah telah melakukan berbagai upaya perbaikan dan pengembangan pendidikan. Salah satunya adalah dengan adanya pengembangan kurikulum yang terus berganti dari tahun ke tahun. Hingga saat ini, kurikulum 2013 dipandang sebagai kurikulum yang tepat untuk mengembangkan potensi dan karakter siswa.

Tujuan tersebut seharusnya bisa diwujudkan melalui kurikulum 2013 yang mencakup aspek afektif, kognitif, dan psikomotorik yang sangat mendukung pengembangan karakter siswa. Selain itu, pemerintah telah mengatur pendidikan karakter melalui Permendikbud Nomor 23 Tahun 201 Tentang Penumbuhan Budi Pekerti.
Namun, data dan fakta di lapangan menunjukkan bahwa tingkat degradasi moral di Indonesia meningkat dari tahun ke tahun.

Degradasi moral yang cenderung meningkat tersebut tentu mengindikasikan kurangnya pendidikan karakter yang dilaksanakan dalam lembaga pendidikan. Oleh karena itu, pemerintah mengeluarkan Perpres Nomor 87 Tahun 2017 Tentang Penguatan Pendidikan Karakter yang mengatur penguatan karakter religius, nasionalis, mandiri, gotong-royong, dan integritas. Nilai religius dan nasionalisme yang merupakan kristalisasi dari beberapa nilai karakter menjadi karakter yang penting untuk dikembangkan guna mengatasi degradasi moral tersebut.

Religius dan nasionalisme merupakan dua nilai karakter yang penting untuk dikembangkan dalam pendidikan. Nasionalisme penting untuk dikembangkan mengingat Indonesia adalah kepulauan yang mulikultural. Indonesia memiliki 13.466 pulau dan berbatasan tiga negara, yakni Papua New Guinea, Malaysia, dan Timor Leste. Kondisi tersebut menjadikan Indonesia sebagai bangsa yang rawan konflik dan rawan separatisme. Rentetan peristiwa seperti perebutan wilayah dengan negara lain dan upaya melepaskan diri yang dilakukan oleh masyarakat menjadi perhatian bagi kita akan pentingnya membangun ketahanan bangsa melalui pemupukan nasionalisme pada generasi muda, terutama dalam lingkungan pendidikan. 
Nilai karakter nasionalis merupakan cara berpikir, bersikap, dan berbuat yang menunjukkan kesetiaan, kepedulian, dan penghargaan yang tinggi terhadap bahasa, lingkungan fisik, sosial, budaya, ekonomi, dan politik bangsa, menempatkan kepentingan bangsa dan negara di atas kepentingan diri dan kelompoknya. Sikap nasionalis ditunjukkan melalui sikap apresiasi budaya bangsa sendiri, menjaga kekayaan budaya bangsa, rela berkorban, unggul, dan berprestasi, cinta tanah air, menjaga lingkungan, taat hukum, disiplin, menghormati keragaman budaya, suku, dan agama (www.depkes.go.id).

Ilmu Pengetahuan Sosial merupakan mata pelajaran yang memiliki peran penting dalam membangun karakter bangsa, terutama karakter nasionalisme.

Nilai-nilai karakter nasionalis dan religius tersebut dapat diintegrasikan ke dalam mata pelajaran wajib di sekolah, termasuk mata pelajaran Ilmu Pengetahuan Sosial (IPS). Ilmu Pengetahuan Sosial sebagai mata pelajaran dan disiplin ilmu memiliki beberapa landasan. Salah satu landasan tersebut adalah landasan ideologis yang menjadi sistem gagasan mendasar untuk memberi pertimbangan dan menjawab pertanyaan: (1) bagaimana keterkaitan antara das sein Ilmu Pengetahuan Sosial (IPS) sebagai pendidikan disiplin ilmu dan das solen Ilmu Pengetahuan Sosial; dan (2) bagaimana keterkaitan antara teoriteori pendidikan dengan hakikat dan praktis etika, moral, politik dan normanorma perilaku dalam membangun dan mengembangkan Ilmu Pengetahuan Sosial (Sapriya, 2009:16).

Berdasarkan landasan ideologis tersebut, jelas bahwa Ilmu Pengetahuan Sosial memiliki peran penting untuk membangun karakter masyarakat, khususnya adalah remaja. Abu Su'ud (2008:11) menyampaikan bahwa pendidikan Ilmu Pengetahuan Sosial, dalam arti Studi Sosial, memiliki tanggung jawab utama untuk membantu anak-anak menjadi dewasa, yakni seseorang yang mampu mengambil keputusan-keputusan penting yang berkaitan dengan pergaulannya dengan orang lain dalam masyarakat, dan berani bertanggung jawab atas apa yang dilakukannya. Selain itu, Ilmu Pengetahuan Sosial diharapkan dapat mengembangkan kemampuan anak untuk mengambil keputusan secara rasional dalam menghadapi berbagai masalah dalam hidup, dan mengambil suatu tindakan secara cerdik.

Zuchdi (2010:5) menyatakan bahwa Ilmu Pengetahuan Sosial (IPS) adalah mata pelajaran yang mengkaji seperangkat peristiwa, fakta, konsep, dan generalisasi yang berkaitan dengan isu sosial. Melalui mata pelajaran IPS, peserta didik diarahkan untuk dapat menjadi warga negara Indonesia yang demokratis, dan bertanggungjawab, serta warga dunia yang cinta damai.

SMP Nasima merupakan sekolah model PPK yang mengunggulkan karakter agamis dan nasionalisme sebagai model pendidikannya. Sebagai sekolah model PPK yang berbasis kelas, SMP Nasima idealnya telah mengimplementasikan nilai religius 
dan nasionalisme dalam setiap mata pelajaran, termasuk mata pelajaran IPS. Dengan demikian, siswa SMP Nasima mampu menjadi insan berkarakter yang takwa kepada Tuhan Yang Maha Esa dan mencintai tanah airnya sebagaimana amanat dalam UU No. 20 Tahun 2003 tentang Tujuan Pendidikan Nasional.

\section{METODE PENELITIAN}

Penelitian ini dikaji menggunakan metode penelitian kualitatif. Menurut Sugiyono (2014: 1), metode penelitian kualitatif adalah metode penelitian digunakan untuk meneliti pada kondisi obyek yang alamiah, (sebagai lawannya adalah eksperimen) dimana peneliti adalah sebagai instrumen kunci, pengambilan sampel sumber data dilakukan secara purposive dan snowball, teknik pengumpulan dengan triangulasi (gabungan), analisis data bersifat induktif/kualitatif, dan hasil penelitian kualitatif lebih menekankan makna daripada generalisasi.

Penelitian ini dilakukan di SMP Nasima Semarang. Alasan pemilihan lokasi penelitian ini karena SMP Nasima Semarang merupakan sekolah piloting implementasi PPK berdasarkan SK Dirjen Pendidikan Dasar dan Menengah Kemendikbud No. 2986.1/D3/-KP/2016 tertanggal 27 Oktober 2016. Lebih dari itu, SMP Nasima Semarang telah menerapkan nilai-nilai nasionalisme dan religius sejak didirikan. Hal tersebut terlihat dari nama sekolah yang dipilih, yakni Nasima. Nasima merupakan akronim dari Nasionalisme dan Agama. Nilai tersebut kemudian dijabarkan dalam visi, misi, dan terumus dalam bentuk semboyan "Nasima Yes". Penelitian ini dilakukan selama dua bulan, yaitu dari bulan Juli s.d. Agustus 2018. Pada penelitian ini menggunakan tiga sumber data yaitu informan, kenyataan yang diamati atau hasil observasi dan dokumen. Teknik pengumpulan data dalam penelitian ini menggunakan beberapa metode yaitu observasi, wawancara mendalam dan dokumen. Dalam penelitian ini menggunakan teknik triangulasi sumber yaitu mengarahkan peneliti agar di dalam mengumpulkan data, ia wajib menggunakan beragam sumber data berbeda dari yang tersedia. Menurut Miles \& Huberman daalm Sugiyono (2014:91), terdapat tiga komponen utama dalam analisis penelitian kualitatif yang meliputi reduksi data, sajian data, dan penarikan simpulan/ verifikasi.

\section{HASIL DAN PEMBAHASAN}

SMP Nasima Semarang merupakan bagian dari Yayasan Pendidikan Islam Nasima (YPI) yang berdiri pada tanggal 7 Januari 1994 atau 24 Rajab 1414 H. SMP Nasima terletak di Jalan Tri Lomba Juang No.1 Semarang. Secara geografis, letak SMP Nasima cukup strategis karena berada di tengah kota. SMP Nasima berbatasan dengan pom bensin dan Jalan Raya Thamrin di sebelah utara, gedung Tri Lomba Juang di sebelah selatan, Jalan Raya Mugas di sebelah timur, dan kampus Unisbank di sebelah barat. Gedung SMP Nasima memiliki warna utama merah dan putih. Warna tersebut merupakan ciri 
fisik karakter nasionalisme dan religius yang ditunjukkan oleh SMP Nasima.

Surat Keputusan Direktur Pembinaan Sekolah Menengah Pertama Dirjen Pendidikan Dasar dan Menengah Kemendikbud RI nomor 2986.1/D3/KP/2016

Tentang

Penetapan Sekolah Menengah Pertama Piloting Program Penguatan Pendidikan Karakter (PPK) Tahun 2006 menetapkan SMP Nasima sebagai salah satu sekolah piloting PPK.

Implementasi

Pendidikan Karakter (PPK)

Nasionalisme dan Religius di SMP Nasima meliputi perencananaan, pelaksanaan, dan evaluasi program.

\section{a. Perencanaan}

Perencanaan program Penguatan Pendidikan Karakter (PPK) nasionalisme dan religius di SMP Nasima dilakukan dengan penyusunan program kerja sekolah jangka panjang, menengah, dan tahunan. Dalam penyusunan program kerja tersaebut, ada tiga bidang yang digarap, yaitu bidang krikulum dan pengajaran, kesiswaan, serta administrasi sekolah dan sarana prasarana. Tiga bidang tersebut dirapatkan sehingga guru dan karyawan bisa memberikan masukan dan saran agar program ketiga bidang tersebut sejalan dengan Penguatan Pendidikan Karakter (PPK) Nasionalisme dan Religius.

\section{b. Pelaksanaan}

Implementasi

Pendidikan Karakter

Penguatan nasionalisme dan religius di SMP
Nasima dilakukan melalui pembiasaan (rutinitas), kegiatan pembelajaran, dan dukungan masyarakat.

Kegiatan pembiasaan atau lebih dikenal dengan budaya sekolah Nasima merupakan kegiatan rutin yang dilakukan siswa setiap hari. Pembiasaan atau budaya sekolah tersebut dimulai ketika siswa memasuki gerbang sekolah hingga mereka keluar dari gerbang sekolah. Adapun program penanaman karakter nasionalisme dan religius yang dilakukan melalui pembiasaan meliputi: a) Penyambutan siswa oleh guru piket dengan senyum, sapa, dan salim; b) Iqrar, yaitu berjanji atas nama agama dan bangsa sesuai visi dan misi SMP Nasima; c) Hormat bendera; d) Menyanyikan lagu Indonesia Raya tiga stansa, mars dan hymne Nasima; e) Pembacaan asmaul husna dan tadarus Al-Qur'an; f) Motivasi dari wali kelas; g) Makan siang bersama dengan adab berdoa dan sopan santun; h) Salat Zuhur dan Asar berjamaah; i) Menyanyikan lagu wajib nasional sebelum pulang; j) Hormat bendera; serta k) Berdoa sebelum pulang.

$$
\text { Implementasi Penguatan }
$$

Pendidikan Karakter (PPK) nasionalisme dan religius dalam pembelajaran dilakukan secara eksplisit dalam proses pembelajaran. Integrasi nilai-nilai tersebut dilakukan melalui proses perencanaan, kegiatan pembelajaran, dan penilain. Penguatan Pendidikan Karakter (PPK) nasionalisme dan religius diimplementasikan dalam kegiatan pembelajaran dengan cara menghubungkan materi yang sedang 
dipelajari dengan kehidupan seharihari. Selanjutnya, guru menyampaikan nilai-nilai atau sikap yang seharusnya dilakukan siswa terkait materi tersebut.

Sosialisasi dengan masyarakat dalam implementasi Penguatan Pendidikan Karakter (PPK) meliputi kegiatan-kegaiatan atau event yang melibatkan masyarakat, baik sebagai narasumber kegiatan atau mitra kegiatan. Contoh keterlibatan masyarakat dalam implementasi Penguatan Pendidikan Karakter (PPK) nasionalisme dapat dilihat pada perayaan Hari Kemerdekaan Republik Indonesia yang ke-73. Dalam event tersebut, SMP Nasima mendatangkan veteran perang untuk memberikan inspirasi kepada peserta didik agar berjuang mempertahankan kemerdekaan Indonesia. Selain itu, ketika Hari Raya Idul Adha, SMP Nasima mengadakan program berlatih berkurban yang mana seluruh daging kurban tersebut dibagikan kepada masyarakat.

\section{c. Evaluasi}

Evaluasi terhadap implementasi Penguatan Pendidikan Karakter (PPK) Nasionalisme dan Religius dilakukan minimal satu semester sekali. Evaluasi dilakukan oleh kepala sekolah bersama guru-guru senior di setiap kelas. Setiap bulan, wali kelas yang berkantor di ruang kelas membuat laporan wali kelas yang didalamnya sudah ada penguatan karakter itu sendiri. Kepala sekolah pun disupervisi oleh pengawas SMP tingkat Kota Semarang. SMP Nasima juga pernah kedatangan dari pihak Kemdikbud untuk memonitoring implementasi Penguatan Pendidikan Karakter (PPK) di SMP Nasima.

\section{PPK nasionalisme dan religius dalam pembelajaran IPS}

Implementasi

Penguatan

Pendidikan Karakter (PPK)

nasionalisme dan religius dalam

pembelajaran IPS dilakukan dalam proses perencanaan, kegiatan pembelajaran, dan penilaian secara terstruktur dan sistematis.

\section{a. Perencanaan Pembelajaran}

Implementasi Penguatan

Pendidikan Karakter (PPK)

nasionalisme dan religius dalam pembelajaran IPS diawali dengan perencanaan. Perencanaan pembelajaran dibuat oleh guru dalam bentuk perangkat pembelajaran yang meliputi program tahunan (prota), program semester (promes), silabus, dan Rencana Pelaksanaan Pembelajaran (RPP). Prota merupakan rencana pembelajaran yang dilakukan oleh guru dan siswa selama satu tahun ajaran. Promes adalah rencana pembelajaran yang dilakukan oleh guru dan siswa selama satu semester, baik semester ganjil maupun genap. Silabus adalah perencanaan pembelajaran yang dilakukan oleh guru dan siswa setiap Kompetensi Inti (KI). Adapun Rencana Pelaksanaan Pembelajaran (RPP) adalah rencana pembelajaran yang akan dilakukan oleh guru dan siswa dalam setiap pertemuan.

Implentasi Penguatan Pendidikan Karakter (PPK) nasionalisme dan religius dalam pembelajaran IPS di SMP Nasima dapat dilihat dari 
Rencana Pelaksanaan Pembelajaran (RPP). Rencana Pelaksanaan Pembelajaran (RPP) dibuat oleh guru IPS di awal tahun ajaran sebagai syarat kelengkapan administrasi pembelajaran. Setiap Rencana Pelaksanaan Pembelajaran (RPP) selalu mencantumkan karakter yang ingin dimunculkan dalam kegiatan inti pembelajaran.

\section{b. Kegiatan Pembelajaran}

Kegiatan pembelajaran merupakan wujud nyata implementasi Penguatan Pendidikan Karakter (PPK) nasionalisme dan religius dalam pelajaran IPS. Kegiatan pembelajaran dari tahapan kegiatan pendahuluan, inti, dan penutup dipilih dan dilaksanakan agar peserta didik mempraktikkan nilai-nilai karakter yang ditargetkan. Dalam pelaksanaan pembelajaran IPS, guru menerapkan prinsip Contextual Taching and Learning (CTL). Contextual Teaching and Learning merupakan konsep pembelajaran yang membantu guru dalam mengaitkan materi pelajaran dengan kehidupan nyata, memotivasi siswa membuat hubungan antara pengetahuan yang dipelajarinya dengan kehidupan mereka (Kementerian Pendidikan Nasional, 2010:39).

\section{c. Evaluasi Pencapaian Belajar}

Pada Dasarnya authentic assessment diaplikasikan dalam proses evaluasi pembelajaran. Teknik dan instrumen penilaian yang dipilih dan dilaksanakan tidak hanya mengukur pencapaian akademik/kognitif siswa, tetapi juga mengukur perkembangan kepribadian siswa.
Implementasi Pendidikan Karakter (PPK) nasionalisme dan religius dalam penilaian pembelajaran dilakukan melalui observasi. Guru IPS mengimplementasikan nilai-nilai Pendidikan Karakter (PPK) nasionalisme dan religius dalam penilaian pembelajaran dengan membuat form penilaian. Tidak ada aturan baku dalam pembuatan form penilaian tersebut. setiap guru memiliki kriteria penilaian yang berbeda dengan guru yang lain. Namun, secara umum form penilaian tersebut berupa kolom yang berisi nomor, nama siswa, aspek penilaian, dan skor atau nilai.

\section{Faktor penghambat dan solusi}

Secara umum tidak ada penghambat yang terlalu berarti dalam implementasi Penguatan Pendidikan Karakter (PPK) Nasionalisme dan Religius dalam pembelajaran IPS di SMP Nasima Semarang. Hambatan yang dihadapi guru IPS di SMP Nasima saat ini adalah terkait dalam upaya konsistensi dan kontinuitas dalam internalisasi nilai-nilai Penguatan Pendidikan Karakter (PPK) Nasionalisme dan Religius dalam diri siswa. Hal tersebut dikarenakan tujuan akhir dari pembiasaan adalah kemampuan guru untuk mengendapkan nilai-nilai tertentu dalam alam bawah sadar siswa. Sehingga, ketika siswa sudah keluar dari SMP Nasima, siswa tetap melaksanakan nilai-nilai yang dipelajarinya ketika belajar di SMP Nasima. Sebagai contoh, siswa yang sudah keluar dari SMP Nasima tetap memiliki sikap hormat terhadap 
bendera yang sedang dikobarkan atau ketika adzan sedang dikumandangkan.

Adapun upaya yang dilakukan untuk mengatasi hambatan tersebut dengan mengulang-ulang kebiasaan yang sama dalam jangka waktu yang lama. Internalisasi nilai-nilai Penguatan Pendidikan Karakter (PPK) Nasionalisme dan Religius adalah dengan menjadikan pembiasaan sebagai sebuah sistem yang dikemas dalam bentuk budaya sekolah.

Adapun kebijakan yang diterapkan oleh kepala sekolah untuk mengatasi hambatan dalam implementasi Penguatan Pendidikan Karakter (PPK) Nasionalisme dan Religius secara umum, yakni pembinaan pagi, pengembangan diri, dan pemberian reward.

\section{Faktor pendukung}

Secara umum, terdapat tiga faktor yang mendukung implementasi Penguatan Pendidikan Karakter (PPK) Nasionalisme dan Religius dalam pembelajaran IPS di SMP Nasima yaitu guru yang berkualitas, sarana dan prasarana, dan dukungan orang tua.

a) Guru yang berkualitas

Di SMP Nasima terdapat tiga guru yang mengampu mata pelajaran IPS, yakni Bapak Taryadi, S.Pd., Ibu Yudina Tri Heriyanti, S.Pd., dan Ibu Chisa Nur Rovikoh, S.Pd. Dilihat dari latar belakang akademiknya, ketiga guru tersebut merupakan lulusan LPTK ternama di Semarang, yakni Universitas Negeri Semarang. Bapak Taryadi mengajar di SMP Nasima selama 17 tahun. Ibu Yudina mengajar di SMP Nasima selama 8 tahun. Dan
Ibu Chisa mengajar di SMP Nasima selama 2 tahun.

Berdasarkan pengamatan yang dilakukan peneliti, ketiga guru IPS di SMP Nasima telah mampu mengoperasikan laptop, LCD, dan proyektor dengan baik. Hal tersebut menunjukkan bahwa mereka tidak gagap teknologi. Adapun metode yang digunakan dalam pembelajaran tidak monoton ceramah. Mereka menggunakan variasi diskusi dan tenya jawab untuk menggali keingin tahuan siswa terhadap materi yang sedang dipelajari. Guru di SMP Nasima dapat mengikuti perkembanagn informasi dengan baik dan mampu menyampaikannya kepada siswa dengan cara mengaitkannya dengan pelajaran yang sedang dipelajarai. Dengan demikian, dapat disimpulkan bahwa kualitas guru IPS di SMP Nasima sudah baik.

b) Sarana dan prasarana

SMP Nasima memiliki fasilitas dan sarana prasarana yang lengkap untuk menunjang pembelajaran. Di setiap kelas, terdapat LCD, proyektor, speaker, white board, AC, CCTV, dan perpustakaan mini yang menjadikan kegiatan pembelajaran lebih nyaman.

SMP Nasima mendesain bahwa seluruh ruang di sekolah memiliki nama-nama kota di seluruh Indonesia. Contoh, ruang saya ini ruang Sumedang. Jadi mengenalkan di mana Sumedang itu berada. Di ruang lain juga demikian. Dimana setiap display kelas para siswa harus tau persis potensi di kelas mereka sesuai nama ruangnya. Misal kelas 8C memiliki nama ruang Pangkalan Mbun. Maka 
siswa harus memiliki referensi yang terdisplay di papan pajang. Pangkalan Mbun itu di mana? Apa kekayaan atau potensinya? Bagaimana adat-istiadat budayanya? Jadi dari nama kelas saja sudah menggugah anak untuk mengenal daerah di Indonesia. Secara tidak langsung, hal tersebut mempermudah guru IPS dalam mengenalkan wilayah Indonesia kepada siswa.

c) Dukungan Orang Tua

Dukungan orang tua dalam implementasi Penguatan Pendidikan Karakter (PPK) Nasionalisme dan Religius lebih bersifat global atau menyeluruh, tidak hanya tertuju pada pemebelajaran IPS. Namun, dukungan terhadap pembelajaran IPS terlihat dari ketersediaan sumber belajar yang lengkap. Setiap siswa di SMP Nasima memiliki buku pegangan IPS, baik yang berasal dari perpustakaan maupun membeli sendiri berdasarkan arahan guru. Selain itu, siswa juga memiliki sumber belajar yang cukup untuk menunjang pembelajaran, misalnya atlas dan laptop. Bahan-bahan penugasan dibawa sendiri oleh siswa dari rumah. Misalnya, ketika Ibu Yudina memberi tugas untuk menggambar peta, siswa telah membawa bahan-bahan yang dibutuhkan dari rumah. Bahan-bahan tersebut meliputi kertas manila, krayon, dan atlas. Hal tersebut menunjukkan bahwa dukungan orang tua dalam menunjang pembelajaran IPS di SMP Nasima sudah baik.

\section{KESIMPULAN}

Berdasarkan hasil penelitian dan pembahasan, maka dapat disimpulkan bahwa:

1. Implementasi Penguatan

Pendidikan Karakter (PPK)

Nasionalisme dan Religius di SMP

Nasima Semarang dilakukan

melalui keteladanan, terintegrasi

dalam perangkat pembelajaran,

pengembangan metode

pembelajaran yang

mengembangkan kemampuan

berpikir kritis, kreatif, komunikatif,

dan kolaboratif, serta melalui optimalisasi fungsi MGMP baik di dalam maupun di luar sekolah. Implementasi Penguatan Pendidikan Karakter (PPK) Nasionalisme dan Religius dalam pembelajaran IPS dilakukan dalam semua proses pembelajaran, meliputi perencanaan pembelajaran, pelaksanaan pembelajaran, serta evaluasi pencapaian belajar.

2. Hambatan yang dihadapi guru IPS di SMP Nasima saat ini terkait dengan upaya konsistensi dan kontinuitas dalam menginternalisasikan nilai-nilai Penguatan Pendidikan Karakter (PPK) Nasionalisme dan Religius dalam diri siswa. Upaya yang dilakukan untuk mengatasi hambatan tersebut adalah mengulang-ngulang kebiasaan yang sama dalam jangka waktu yang lama. Dalam lingkup sekolah, terdapat tiga kebijakan yang dilakukan oleh kepala sekolah, 
3. yakni pembinaan setiap pagi, pengembangan diri, dan pemberian reward atau hadiah kepada para guru yang memenuhi kriteria tertentu. Adapun faktor pendukung Implementasi Penguatan Pendidikan Karakter (PPK) Nasionalisme dan Religius dalam pembelajaran IPS di SMP Nasima Semarang meliputi guru yang berkualitas, sarana dan prasarana yang lengkap.

Agar implementasi PPK Nasionalisme dan Religius dalam pembelajaran IPS berjalan dengan maksimal, maka guru IPS perlu meningkatkan intensitas implementasi Penguatan Pendidikan Karakter (PPK), khususnya nasionalisme dan religius melalui pembelajaran IPS di dalam kelas. Selain itu, guru IPS perlu menularkan pemahaman dan kemampuan implementasi Penguatan Pendidikan Karakter (PPK), khususnya nasionalisme dan religius kepada guru lain di Nasima dan sesama guru IPS di sekolah lain.

\section{DAFTAR PUSTAKA}

Dalmeri. 2014. 'Pendidikan Untuk Pengembangan Karakter (Telaah terhadap Gagasan Thomas Lickona dalam Educating for Character)'. Dalam Al-Ulum. No. 1. Hal. 269-288.

Kementerian Kesehatan Republik Indonesia. 2018. Penguatan
Pendidikan Karakter Jadi Pintu Masuk Pembenahan Pendidikan Nasional. Diunduh melalui www.depkes.go.id pada 20 April 2018.

Kementerian Pendidikan dan Kebudayaan Republik Indonesia. 2017. Konsep dan Pedoman Penguatan Pendidikan Karakter. Diunduh melalui http://cerdasberkarakter.kemendi kbud.go.id pada 22 April 2018.

Peraturan Presiden Republik Indonesia Nomor 87 Tahun 2017 tentang Penguatan Pendidikan Karakter. Salinan diunduh melalui http://setkab.go.id/wpcontent/uploads/2017/09/Perpres _Nomor_87_Tahun_2017 pada 27 Desember 2017 pukul 07:52 WIB.

Sapriya. 2009. Pendidikan IPS. Bandung: Remaja Rosdakarya.

Undang-Undang Republik Indonesia Nomor 20 Tahun 2003 tentang Sistem Pendidikan Nasional. Diunduh melalui http://kelembagaan.ristekdikti.go .id pada 27 Desember 2017 pukul 09:11 WIB.

Zuchdi, Darmiyati, Zuhdan K.P., dan Muhsinatun S.M. 2010. Pengembangan Model Pendidikan Karakter Terintegrasi Dalam Pembelajaran Bidang Studi di Sekolah Dasar. Cakrawala Pendidikan. Edisi Khusus Dies Natalis UNY. 